\title{
Which patients wait longer to be seen and when? A waiting time study in the emergency department
}

N. Elkum, ${ }^{1}$ M. Fahim, ${ }^{2}$ M. Shoukri ${ }^{1}$ and A. Al-Madouj ${ }^{1}$

$$
\begin{aligned}
& \text { أي المرضى يطول انتظارهم قبل أن ير اهم الطبيب ومتى؟ دراسة لزمن الانتظار في قسم الإسعاف }
\end{aligned}
$$

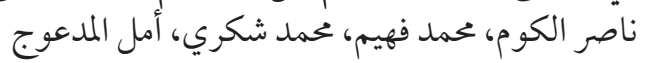

الخلاصـة: درس الباحثون زمن الانتظار لدى المرضى إلى أن يراهم الطبيب في قسم الإسعاف مستشفى للرعاية

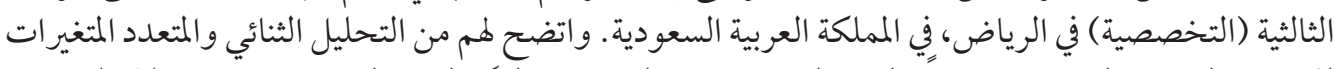

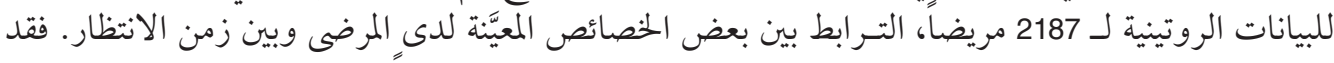

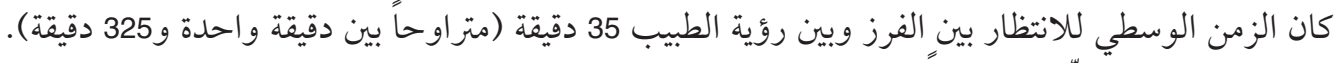

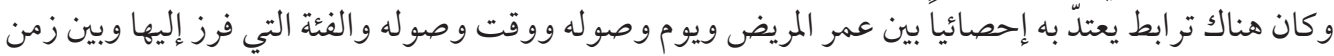

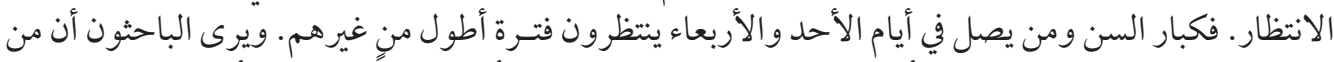

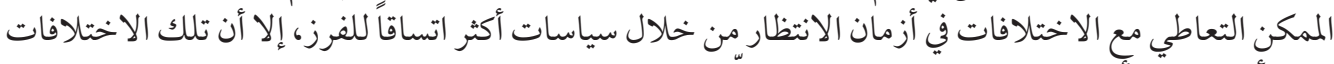

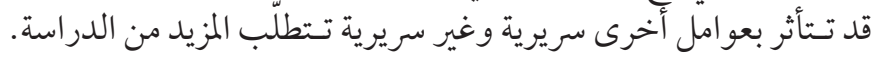

ABSTRACT We investigated the waiting time for patients before seeing a physician in the emergency department of a tertiary care hospital in Riyadh, Saudi Arabia. Bi- and multivariate analyses of routine data for 2187 patients determined the association between selected patient characteristics and waiting time. The median waiting time between triage and being seen by a physician was 35.0 min (range 1.0-325.0 min). Age, day of arrival, time of arrival and triage category were significantly associated with waiting time. Older patients and those arriving on Sundays and Wednesdays waited longer. Variability in waiting times could be addressed by more standardized triage policies, but may also be influenced by other clinical or non-clinical factors that require further investigation.

Critères de tri et circonstances : une étude sur les délais d'attente dans un service d'urgences RÉSUMÉ Nous nous sommes penchés sur le temps que devaient attendre les patients avant d'être examinés par un médecin au service des urgences d'un hôpital de soins tertiaires de Riyad (Arabie saoudite). L'analyse bivariée et multivariée des données de routine relatives à 2187 patients a permis d'établir un lien entre certaines caractéristiques de ces patients et les délais d'attente. Le délai d'attente médian entre le tri et la consultation par un médecin était de 35 minutes (avec des extrêmes allant de 1 à 325 minutes). L'âge, le jour d'arrivée, l'heure d'arrivée et la catégorie de tri étaient significativement associés au délai d'attente. Les sujets âgés et ceux qui se présentaient un dimanche ou un mercredi devaient attendre plus longtemps. Il est possible de remédier à la variabilité des temps d'attente grâce à des politiques plus normalisées en matière de tri des patients, mais cette variabilité peut également être influencée par d'autres facteurs cliniques et non cliniques exigeant des études plus approfondies.

${ }^{1}$ Department of Biostatistics, Epidemiology and Scientific Computing; ${ }^{2}$ Emergency Department, King Faisal Specialist Hospital and Research Centre, Riyadh, Saudi Arabia (Correspondence to N. Elkum:

nelkum@hotmail.com).

Received: 01/06/06; accepted: 29/10/06

المجلة الصحية لشرق المتوسط، منظمة الصحة العالمية، المجلد الخامس عشر، العدد Y، 9 +. 


\section{Introduction}

Overcrowding of the emergency department (ED) has become an increasing problem for hospitals around the world. The $2003 \mathrm{Na}$ tional Hospital Ambulatory Medical Care Survey reported an increasing trend in ED utilization rates for patients aged over 22 years from 1993-2003 in United States hospitals [1]. It also reported 3.2 hours as an average waiting time in the ED, which included 46.5 minutes spent waiting to be seen by a physician. Emergency care is typically sought for a serious accidental injury or sudden onset of an acute medical condition, such as a suspected heart attack or a stroke. A large segment of patient visits, however, are for less critical problems and the processing of these patients can result in delayed management of more acutely ill patients. Longer waiting times in the ED not only contribute to patients' dissatisfaction with the care received [2] but may result in protracted pain and suffering and in delays in diagnosis and treatment $[3,4]$.

Several studies have identified prolonged waiting times as the main component of patient dissatisfaction, as well as the most frequent reason patients leave before medical evaluation. Many of these patients are seriously ill [5-8]. Mohsin et al. addressed the association between selected socioeconomic characteristics of Australian emergency patients with waiting times [9]. Goodacre and Webster from the United Kingdom concluded that the time of presentation was the most powerful predictor of the waiting time to see a doctor [10]. However, these studies were done in areas where there were large integrated health care systems already established, unlike in Saudi Arabia where patients do not necessarily have an identifiable primary care provider. Additionally, our patient population has unique cultural and linguistic features that are not present in other studies.
King Faisal Specialist Hospital and Research Centre is a major tertiary care centre serving patients referred from all over Saudi Arabia, and hence the expectations of these patients are very high. The ED is one of the important entry points to the health care system in our institution. The excessive lengths of time patients may wait before treatment in the ED may negatively colour their perceptions of care provided during such visits. Our aim is to minimize waiting time by understanding the delays and their causes inherent in the process of care in the ED. The ED is integrated with the majority of departments in the hospital; therefore, system improvements are necessary to reduce the length of stay in the ED. This study explored the association between selected patients characteristics and waiting time, and determined how each characteristic contributed to the overall length of stay.

\section{Methods}

This was a retrospective study in a major tertiary care referral centre carried out on patients who visited the ED during the year 2001-02. The study was approved by the Research Advisory Council (Institutional Review Board) of King Faisal Specialist Hospital and Research Centre.

\section{Sample}

A sample of 25 charts was randomly selected every day for 4 months (November 2001-February 2002) from patients' medical records.

\section{Data collection}

ED patient times were recorded on the patient's chart during his/her visit by the registration clerk, triage nurse and evaluating physician. The triage level was assigned by the triage nurse upon initial triage assessment and was categorized into 3 levels: 
emergent, urgent and non-urgent (emergent being the sickest). The following variables were collected: day of arrival, demographic data, registration time, triage level, room assignment time, and the time interval from physician assessment to decision. Time of arrival in the ED was defined as the time a patient first approached the registration desk to express his or her desire to be treated. Waiting time, the period spent waiting to be seen by a physician, was defined as the difference between the time that triage started and the time when the patient was seen by a physician.

Because of the large number of patients involved in this study, we developed a data-entry system for collection of ED patient's information on a Palm Pilot personal digital assistant (PDA). The information was downloaded directly from the PDA into a Microsoft Access database for further analysis. This is the first research study using PDAs in this hospital.

\section{Statistical analysis}

Statistical analysis was performed with $S A S$ software, version 9.1. The waiting times were positively skewed; the high degree of skewness prevented analysis by Student $t$-test and least squares regression. Therefore, the univariate relation between each independent factor and waiting times was tested using a non-parametric test. A $P$-value $<0.05$ was considered significant. Weibull regression analysis using waiting time as the dependent variable and adjusting for potential confounders was performed to examine adjusted waiting times.

\section{Results}

During the study period the ED was manned by 24 consultants and, on an average, 125 patients were seen in the ED per day. In $2001-02,9.46 \%$ of patients presenting to our ED were admitted to the hospital and $3.11 \%$ left the ED without being seen.

\section{Characteristics of study subjects}

During the study period, 2187 charts were randomly selected from the medical records for patients who triaged in our ED. Of the total patients, $34.9 \%$ were aged $0-14$ years, $40.2 \%$ were $15-44$ years, $16.7 \%$ were $45-64$ years and $8.2 \%$ were $65+$ years. The number of visits to the ED showed a significant association between age and sex $(P<$ $0.0001)$. Of the visits by males, $41.9 \%$ were paediatric cases (aged 0-14 years) whereas of visits by females, $27.7 \%$ were paediatric cases. There were more females than males in the age group $15-44$ years $(45.7 \%$ versus $34.8 \%$ ) and in the age group 45-64 years $(18.9 \%$ versus $14.6 \%)$. Of the total patients, $8 \%$ were expatriates with a similar proportion of males and females.

The distribution of triage status was emergent $(0.6 \%)$, urgent $(42.6 \%)$ and nonurgent $(56.8 \%)$. The greatest number of visits were made on Wednesdays $(22.2 \%)$.

\section{Waiting times}

The median waiting time between triage and being seen by a physician was $35.0 \mathrm{~min}$ (range $1.0 \mathrm{~min}$ to $325.0 \mathrm{~min}$ ). Univariate analysis indicated that waiting times between triage and being seen by a physician varied by age, day of arrival, time of arrival and triage category (Table 1 ).

The mean waiting times differed significantly by age group of patients $(P<0.0001)$ (Figure 1). Patients aged $<65$ years waited the longest whereas paediatric patients ( $0-14$ years) were seen the quickest.

The results also showed that mean waiting times varied by triage category (Figure 2 ) and day of attendance (Figure 3 ). The longest waiting times were observed for those who arrived on Sundays and for triage category urgent. A non-significant asso- 
Table 1 Mean and median waiting times by selected characteristics of emergency department patients $(n=2187)$

\begin{tabular}{|c|c|c|c|c|}
\hline \multirow[t]{2}{*}{ Variable } & \multirow{2}{*}{$\begin{array}{c}\text { No. of } \\
\text { patients }\end{array}$} & \multicolumn{2}{|c|}{ Waiting time (min) } & \multirow[t]{2}{*}{$P$-value ${ }^{a}$} \\
\hline & & Mean (SD) & Median & \\
\hline Sex & & & & 0.1337 \\
\hline Male & 1024 & $48.51(46.30)$ & 35.00 & \\
\hline Female & 978 & $50.70(46.48)$ & 35.00 & \\
\hline Age (years) & & & & $<0.0001$ \\
\hline $0-14$ & 701 & $45.87(43.51)$ & 31.00 & \\
\hline $15-44$ & 796 & $49.20(48.66)$ & 34.00 & \\
\hline $45-64$ & 342 & $54.15(47.58)$ & 39.00 & \\
\hline $65+$ & 163 & $57.85(42.88)$ & 45.00 & \\
\hline Triage category & & & & 0.0013 \\
\hline Emergent & 10 & $30.80(16.57)$ & 33.00 & \\
\hline Urgent & 843 & $52.98(48.42)$ & 39.00 & \\
\hline Non-urgent & 1109 & $47.87(45.24)$ & 33.00 & \\
\hline Nationality & & & & 0.1182 \\
\hline Saudi Arabian & 1839 & $49.27(46.52)$ & 35.00 & \\
\hline Expatriate & 163 & $53.20(44.83)$ & 40.00 & \\
\hline Hospital employee & & & & 0.7749 \\
\hline No & 1679 & $49.26(46.03)$ & 35.00 & \\
\hline Yes & 323 & $51.33(48.23)$ & 35.00 & \\
\hline Day of presentation & & & & $<0.0001$ \\
\hline Saturday & 221 & $51.12(45.71)$ & 35.00 & \\
\hline Sunday & 323 & $55.72(50.18)$ & 41.00 & \\
\hline Monday & 196 & $49.81(46.26)$ & 35.00 & \\
\hline Tuesday & 219 & 41.68 (37.73) & 30.00 & \\
\hline Wednesday & 428 & 55.19 (52.39) & 36.00 & \\
\hline Thursday & 368 & $46.92(42.18)$ & 32.00 & \\
\hline Friday & 247 & $41.34(41.48)$ & 30.00 & \\
\hline Time of presentation & & & & $<0.0001$ \\
\hline 00:01-06:00 & 333 & $56.83(54.15)$ & 38.00 & \\
\hline 06:00-12:00 & 401 & 49.98 (43.19) & 35.00 & \\
\hline $12: 01-18: 00$ & 514 & 56.65 (53.37) & 40.00 & \\
\hline $18: 01-24: 00$ & 751 & 41.28 (36.99) & 30.00 & \\
\hline
\end{tabular}

${ }^{a}$ Kruskal-Wallis test.

$S D=$ standard deviation.

ciation was noticed between mean waiting times and nationality, sex or whether the patient was a hospital employee.

Weibull regression analysis was used to examine the influences of explanatory variables on waiting times of patients (Table 2).
The time between triage and being seen by a doctor was considered the dependent variable. The results showed that age, day of arrival, time of arrival and triage category were significantly associated with the waiting time. Arrival between 00:00 and 06:00 


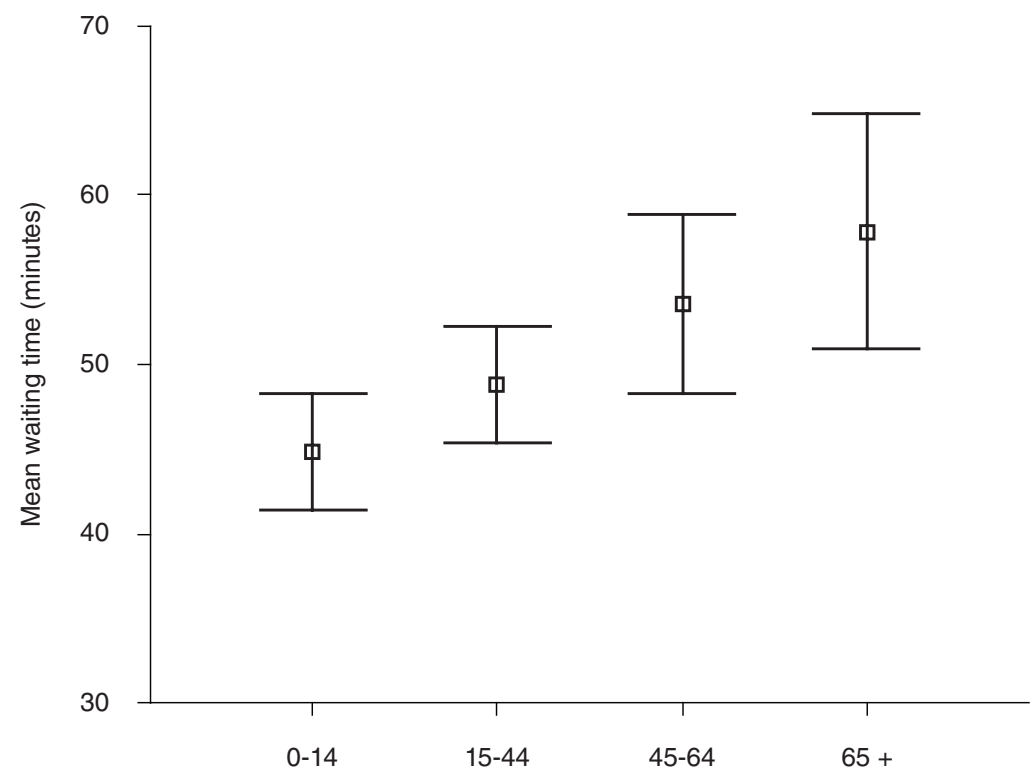

Age groups (years)

Figure 1 Mean waiting time in the emergency department by patient's age

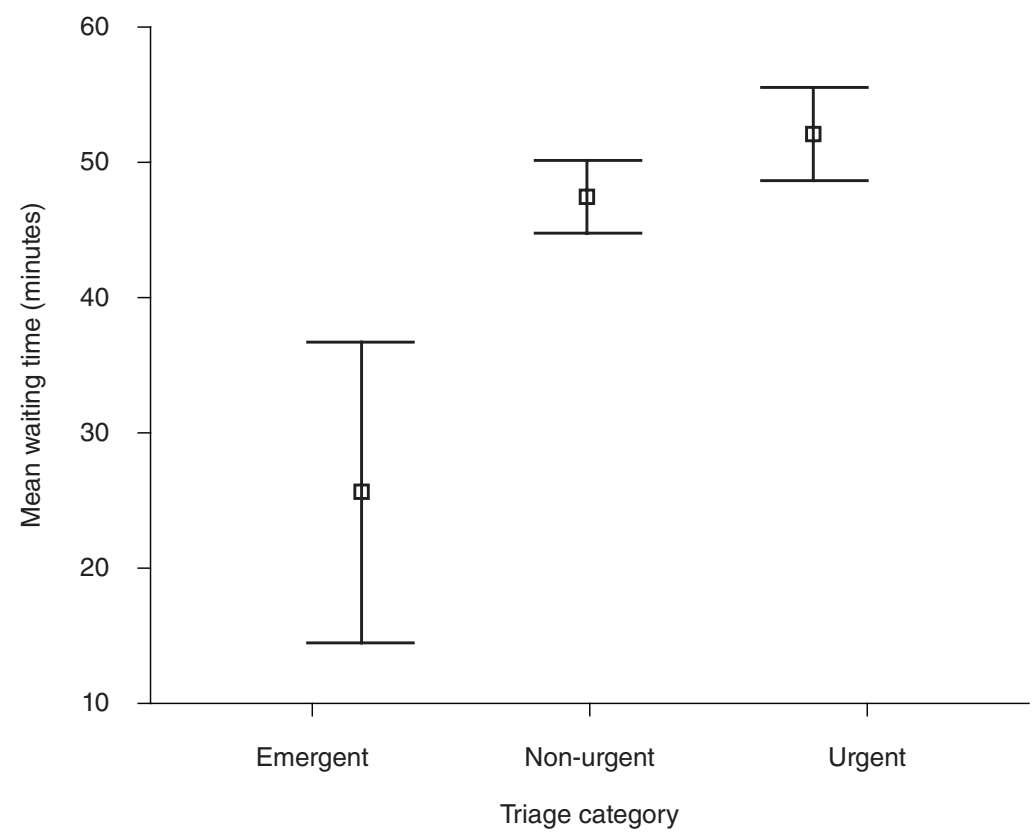

Figure 2 Mean waiting time in the emergency department by triage category

المجلة الصحية لشرق المتوسط، منظمة الصحة العالمية، المجلد الخامس عشر، العدد ب، 9 ·. 


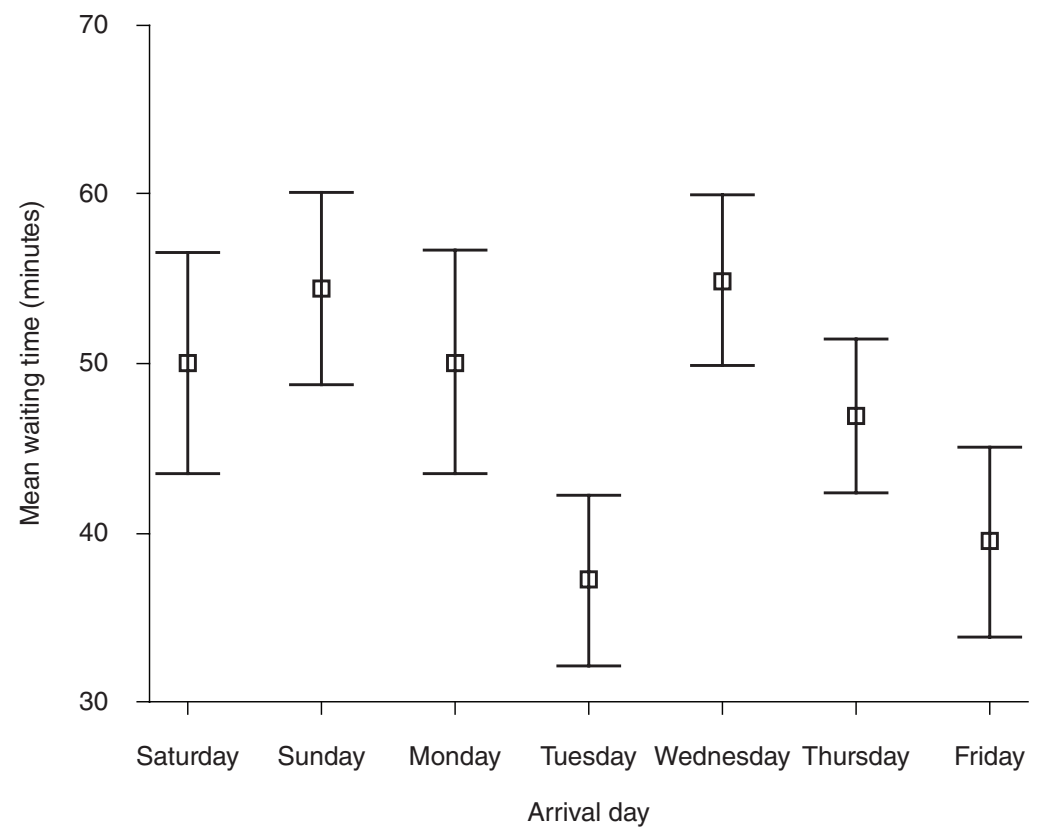

Figure 3 Mean waiting time in the emergency department by day of presentation

hours as well as arrival between 12:00 and 18:00 hours were significantly correlated with longer waiting time. The regression coefficients also indicated that older age and arrival on Sundays and Wednesdays were factors associated with significantly longer waiting time after triage.

\section{Discussion}

The study examined the association between selected characteristics of emergency patients and waiting times in the ED. The findings showed that waiting time between triage and being seen by a physician was associated with age, days of arrival, time of arrival and urgency (triage category). Children aged 0-14 years had more rapid access to emergency medical care than adults. Waiting times for adults aged $65+$ years were significantly longer than for younger ages. This finding could be explained by the inappropriately higher triage level assigned to older patients, recognizing them as a relatively high risk group due to age and higher medical complexity, e.g. higher incidence of multiple medical problems and multisystem disorders.

Patients who were triaged as urgent had longer waiting times than emergent or nonurgent categories. Triage classifications are not standardized locally or internationally. Studies have shown great variability in triage practices among nurses, physicians and software programmes, even in the same ED $[11,12]$. More detailed and standardized triage guidelines may reduce the influence of non-clinical factors on the urgency for and time to receive emergency care. Long waits have the potential to affect patient outcomes unless triage systems are very effective and re-evaluation of patients is 


\begin{tabular}{|c|c|c|c|}
\hline Variable & Regression coefficient & $95 \%$ confidence limit & $P$-value \\
\hline Age & 0.003 & 0.001 to 0.005 & 0.004 \\
\hline \multicolumn{4}{|l|}{ Sex } \\
\hline Male & Reference & & 0.167 \\
\hline Female & 0.065 & -0.0273 to 0.1579 & \\
\hline \multicolumn{4}{|l|}{ Nationality } \\
\hline Saudi Arabian & Reference & & 0.442 \\
\hline Expatriate & 0.066 & -0.1028 to 0.2354 & \\
\hline \multicolumn{4}{|c|}{ Hospital employee } \\
\hline Yes & Reference & & 0.132 \\
\hline No & -0.099 & -0.228 to 0.029 & \\
\hline \multicolumn{4}{|l|}{ Triage category } \\
\hline Urgent & Reference & & \\
\hline Non-urgent & -0.072 & -0.167 to 0.023 & 0.137 \\
\hline Emergent & -0.735 & -1.394 to -0.076 & 0.029 \\
\hline \multicolumn{4}{|c|}{ Day of presentation } \\
\hline Saturday & 0.225 & 0.032 to 0.419 & 0.023 \\
\hline Sunday & 0.313 & 0.138 to 0.488 & 0.001 \\
\hline Monday & 0.250 & 0.054 to 0.447 & 0.013 \\
\hline Tuesday & -0.062 & -0.265 to 0.141 & 0.548 \\
\hline Wednesday & 0.285 & 0.121 to 0.449 & 0.001 \\
\hline Thursday & 0.132 & -0.039 to 0.304 & 0.131 \\
\hline Friday & Reference & & \\
\hline \multicolumn{4}{|c|}{ Time of presentation } \\
\hline 00:01-06:00 & 0.370 & 0.233 to 0.507 & $<0.001$ \\
\hline $06: 00-12: 00$ & 0.228 & 0.099 to 0.357 & $<0.001$ \\
\hline 12:01-18:00 & 0.355 & 0.237 to 0.474 & $<0.001$ \\
\hline $18: 01-24: 00$ & Reference & & \\
\hline
\end{tabular}

adhered to vigorously. Assigning a patient an inappropriately low triage level could lead to delay in care for that patient. Conversely, assigning an inappropriately high triage level to a less severely ill patient leads to delay in care for other, possibly sicker, patients. A new 5-level Canadian nursing triage system was implemented in our ED after our study. A comparative study of the 2 triage systems in the ED is certainly warranted to verify the effectiveness.

Our findings may be related to several potential variables influencing waiting times in the ED. These potential variables may be linked either to the patient, the provider or the system at large. Patientrelated variables potentially include language spoken, socioeconomic status, nationality/ethnicity, eligibility for care at this hospital, geographic location, literacy and cultural values. Provider-related variables may include stereotyping, bias and prejudice which might play a role in triage decisions. The ratios of doctors and nurses to patients might also play a significant role, so might physician burnout due to declin- 
ing manpower. System-related variables may include availability of primary care or other specialty care services, availability of efficient diagnostic facilities, ED volume, availability of unoccupied hospital beds and other allied administrative services. In retrospect, all these variables should be explored in future waiting time studies similar to this one. Additionally, standardization of triage systems and definitions of waiting time would be valuable.

\section{Conclusion}

Our data suggest that patients presenting to our ED have waiting times that vary according to age, triage category, time of arrival and day of arrival. With a growing population and an increasing demand for medical care in ED throughout the Gulf region and elsewhere, there is a need for comparative studies both locally as well as internationally to document and account for avoidable areas of delay in the care of emergency patients and hence improve quality of care. This is the first study of its kind in our institution and serves as a starting point for further comparative studies using newer standardized triage systems for better decision support of the health care in the ED.

\section{References}

1. McCaig LF, Burt CW. National Hospital Ambulatory Medical Care Survey: 2003 emergency department summary. Hyattsville, Maryland, National Center for Health Statistics, 2005 (Advance Data from Vital and Health Statistics, No. 358.).

2. Thompson DA et al. Effects of actual waiting time, perceived waiting time, information delivery, and expressive quality on patient satisfaction in the emergency department. Annals of emergency medicine, 1996, 28(6):657-65.

3. Derlet RW, Richards JR. Overcrowding in the nation's emergency departments: complex causes and disturbing effects. Annals of emergency medicine, 2000, 35(1):63-8.

4. Derlet RW, Richards JR. Emergency department overcrowding in Florida, New York, and Texas. Southern medical journal, 2002, 95(8):846-9.

5. Baker DW, Stevens CD, Brook RH. Patients who leave a public hospital emergency department without being seen by a physician. Causes and consequences. Journal of the American Medical Association, 1991, 266(8):1085-90.
6. Bindman $A B$ et al. Consequences of queuing for care at a public hospital emergency department. Journal of the American Medical Association, 1991, 266(8):1091-6.

7. Dershewitz RA, Paichel W. Patients who leave a pediatric emergency department without treatment. Annals of emergency medicine, 1986, 15(6):717-20.

8. Stock LM et al. Patients who leave emergency departments without being seen by a physician: magnitude of the problem in Los Angeles County. Annals of emergency medicine, 1994, 23(2):294-8.

9. Mohsin $M$, Bauman $A$, leraci $S$. Is there equity in emergency medical care? Waiting times and walk-outs in South Western Sydney hospital emergency departments. Australian health review, 1998, 21(3):133-49.

10. Goodacre S, Webster A. Who waits longest in the emergency department and who leaves without being seen? Emergency medicine journal, 2005, 22(2):93-6. 
11. Brillman JC et al. Triage: limitations in predicting need for emergent care and hospital admission. Annals of emergency medicine, 1996, 27(4):493-500.
12. Wuerz R, Fernandes CM, Alarcon J. Inconsistency of emergency department triage. Emergency Department Operations Research Working Group. Annals of emergency medicine, 1998, 32(4):431-5.

\section{World Malaria Day 25 April 2009}

Malaria continues to haunt $40 \%$ of the world's population. It infects more than 500 million people per year and kills more than 1 million. The burden of malaria is heaviest in sub-Saharan Africa but the disease also afflicts Asia, Latin America, the Middle East and even parts of Europe.

World Malaria Day, which was instituted by the World Health Assembly at its 60th session in May 2007, is a day for recognizing the global effort to provide effective control of malaria.

25 April is a day of unified commemoration of the global effort to provide effective control of malaria around the world. This year's World Malaria Day marks a critical moment in time. The international malaria community has merely 2 years to meet the 2010 targets of delivering effective and affordable protection and treatment to all people at risk of malaria, as called for by the UM Secretary-General, Ban Ki-Moon.

Further information on malaria can be found in the WHO fact sheet M०94 (Updated January 2009) which can be accessed at: http://www. who.int/mediacentre/factsheets/fs094/en/index.html 